\title{
Storage of purified biogas (biomethane) at low pressure
}

\author{
Michael Feroldi ${ }^{1,3 *}$, Andressa Caroline ${ }^{1,3}$ Neves, Carlos Eduardo Borba ${ }^{2}$, Mabel Karina \\ Arantes $^{3}$, Alves Helton José ${ }^{1,3}$ \\ ${ }^{I}$ Universidade Estadual do Oeste do Paraná - Mestrado em Engenharia de Energia na Agricultura, Departamento \\ de Energia na Agricultura, Cascavel, Paraná, Brasil. ${ }^{2}$ Universidade Estadual do Oeste do Paraná - Departamento \\ de Engenharia Química, Toledo, Paraná, Brasil. ${ }^{3}$ Universidade Federal do Paraná - Laboratório de Catálise e \\ Produção de Biocombistíveis, Palotina, Paraná, Brasil.
}

\begin{abstract}
The global use of fossil energy sources has led to the need to develop technologies capable of mitigating its consequences. One such option is anaerobic biodigestion, which is already scientifically well-established, although the use of its main products (biogas and biomethane) still requires further development before they can be employed in automotive vehicles, largely due to technical issues concerning their storage. The storage of methane using adsorption (Adsorbed Natural Gas - ANG) is a technology that requires less energy and moderate pressures and temperatures. However, the main storage techniques continue to be those that involve high pressures and/or cryogenic temperatures. The present work evaluates the performance of an unprecedented prototype developed by UFPR for the storage of methane by adsorption, employing commercial activated carbon. The factorial design (22) indicated that the storage capacity of the system was $39.41 \mathrm{~V} / \mathrm{V}$ using activated carbon, and the desorption process was effective at $60^{\circ} \mathrm{C}$. Thus, the use of adsorbents of low cost and easy access can provide very interesting results (>100 V/V), which contributes to make the technology viable.
\end{abstract}

Keywords: Adsorption, biogas, vehicle fuel.

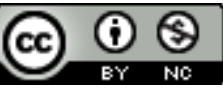

\footnotetext{
*Author for correspondence: michaelferoldi@gmail.com
} 


\section{INTRODUCTION}

The problems associated with the dependence on fossil energy sources, especially petroleum and its derivatives, has increasingly stimulated the development of technologies capable of using biomass for energy production.

Biogas, which can be obtained from a variety of raw materials, is mainly used in direct combustion or in generators for electric power production, and its use in the transport sector has been studied in recent years ${ }^{1}$.

There are many processes in which biogas could be used, but there is an urgent need to resolve the difficulties likely to hinder its viable implementation. The calorific value of biogas is the key factor for its use in energy conversion, and for this reason, different purification techniques are used for methane enrichment, especially involving the removal of $\mathrm{CO}_{2}$ and $\mathrm{H}_{2} \mathrm{~S}^{2}$.

When the methane content reaches around 96\%, the properties of biogas become similar to those of natural gas (a fossil fuel). Therefore, purified biogas can be easily employed as a substitute or together with natural gas in automotive vehicles ${ }^{3}$.

Despite the slow pace of development, the vehicular use of purified biogas (biomethane) has great technological potential, since systems that currently use natural gas (CNG) could shift to the use of biomethane ${ }^{4,5,6}$.

In order to achieve advances in this industrial sector, it is necessary to develop and improve technologies for the transportation and storage of gaseous fuels including natural gas and methane. Among these techniques, adsorption on porous adsorbent solids (ANG - Adsorbed Natural Gas) has attracted considerable interest, since it is less expensive due to the use of moderate pressures and room temperature.

Many solid adsorbent materials can be used for the storage of natural gas/methane, although activated carbon is most extensively used industrially, because it is readily available and can be produced from a wide range of precursor materials ${ }^{7}$.

Advances in research in Brazil are needed in various areas of fuel production and use, considering the needs of small-scale industries and consumers. Adsorbents that are sufficiently abundant and accessible for use in small-scale systems are of particular interest, and one option is the use of activated carbon for methane storage, which is the focus of the present work.

\section{OBJECTIVES}

Given the need for development of the use of gaseous fuels in the vehicular sector, the aims of this work were to construct a methane storage system and to evaluate the storage of methane fuel on activated carbon, considering operational loading/unloading parameters of the system.

\section{METHODS}

Methane storage tests were performed using commercial activated carbon with particle diameter of 3-5 mm (6x10 mesh). The material was dried in an oven at $100^{\circ} \mathrm{C}$ for $24 \mathrm{~h}$ prior to each storage test, in order to avoid interference from moisture.

\section{CHARACTERIZATION}

\section{$\mathbf{N}_{2}$ Physisorption}

The textural characteristics of the carbon used were determined by adsorption/desorption isotherms obtained at liquid nitrogen temperature, employing a Quantachrome Nova 2000e instrument. The samples were pretreated at $200^{\circ} \mathrm{C}$ for $4 \mathrm{~h}$ 
under vacuum in order to remove any moisture and/or organic species adsorbed on the surface of the material. Determination of the predominant porous structure (microporous, mesoporous, or macroporous) employed the specific surface area and pore volume, using the BET (Brunauer-Emmett-Teller) method, and pore diameter was determined by the BJH (Barrett- Joyner-Halenda) adsorption method.

\section{Scanning Electron Microscopy}

Scanning electron microscopy was used to determine the morphology and average size of the particles. The powdered samples were spread onto a double-sided carbon tape attached to the sample holder, then dried and sputter-coated with a thin layer of gold. The micrographs were obtained at several magnifications, in backscattering mode.

\section{METHANE STORAGE TESTS}

The tests were performed in the Laboratory of Catalysis and Biofuels Production (LabCatProBio) of the Federal University of Paraná (Palotina Sector). Pure commercial methane was injected into an unprecedented storage system consisting of a cylinder and a low volume compressor pump, and was subsequently released by heating in an oven at $60^{\circ} \mathrm{C}$ for total desorption of the gas. The storage tests employed a maximum pressure of 10 bar. The pressure and temperature were controlled and measured with a manometer and thermocouples, respectively, connected to the cylinder filled with the adsorbent.

The tests were carried out according to a $2^{2}$ factorial design with triplicates at the central point, varying the adsorption temperature and the rate of methane injection, as shown in Table 1.

Table 1- $2^{2}$ factorial design for the adsorption tests

\begin{tabular}{ccccc}
\hline \multirow{2}{*}{ Test } & \multicolumn{2}{c}{ Temperature } & \multicolumn{2}{c}{ Flow rate } \\
\cline { 2 - 5 } & Codified & ${ }^{\circ} \mathrm{C}$ & Codified & $\mathrm{mL} \mathrm{s}^{-1}$ \\
\hline $\mathbf{1}$ & -1 & 20 & -1 & 3.65 \\
$\mathbf{2}$ & +1 & 40 & -1 & 3.65 \\
$\mathbf{3}$ & -1 & 20 & +1 & 7.3 \\
$\mathbf{4}$ & +1 & 40 & +1 & 7.3 \\
$\mathbf{5}$ & 0 & 30 & 0 & 5.54 \\
$\mathbf{6}$ & 0 & 30 & 0 & 5.54 \\
$\mathbf{7}$ & 0 & 30 & 0 & 5.54 \\
\hline
\end{tabular}

After reaching the required pressure (10 bar), the amount of gas stored was obtained by weighing the system, recording the mass difference between the cylinder + adsorbent and the cylinder + adsorbent $+\mathrm{CH}_{4}$, after which the cylinder was emptied. The mass values were transformed into the volume of methane stored according to the volume of the cylinder (V/V). Finally, the system was heated at the previously established temperature of $60^{\circ} \mathrm{C}$ for total removal of the adsorbed methane molecules from the pores of the adsorbent, regenerating the material for a subsequent adsorption cycle. 


\section{RESULTS}

Figure 1 shows the particles of activated carbon, and Table 2 provides their textural characteristics.

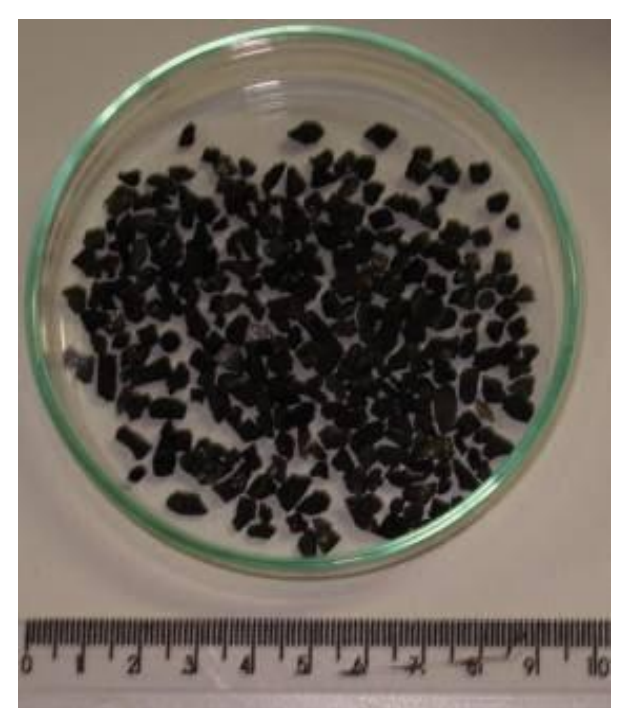

Figure 1- Activated carbon (6x10 mesh).

Table 2. Textural properties of the activated carbon

\begin{tabular}{cccc}
\hline Sample & S BET $\left(\mathbf{m}^{2} \mathbf{g}^{-1}\right)$ & $\begin{array}{c}\text { Pore volume } \\
\left(\mathbf{c m}^{\mathbf{3}} \mathbf{g}^{-1}\right)\end{array}$ & Average pore width $(\mathbf{A})$ (BJH) \\
\hline $6 X 10$ & 774.84 & 0.4532 & 35.62 \\
\hline
\end{tabular}

It can be seen from Table 2 that the activated carbon had a high specific area, which could be attributed to the high pore volume. The average pore diameter was in the mesopore range, according to the IUPAC classification ${ }^{8}$ (mesopores: 20-500 $⿱$ ) ), but with close proximity to the micropore range. Figure 2 shows the isotherms obtained for the activated carbon, which could be classified as type IV, characteristic of mesoporous solids.

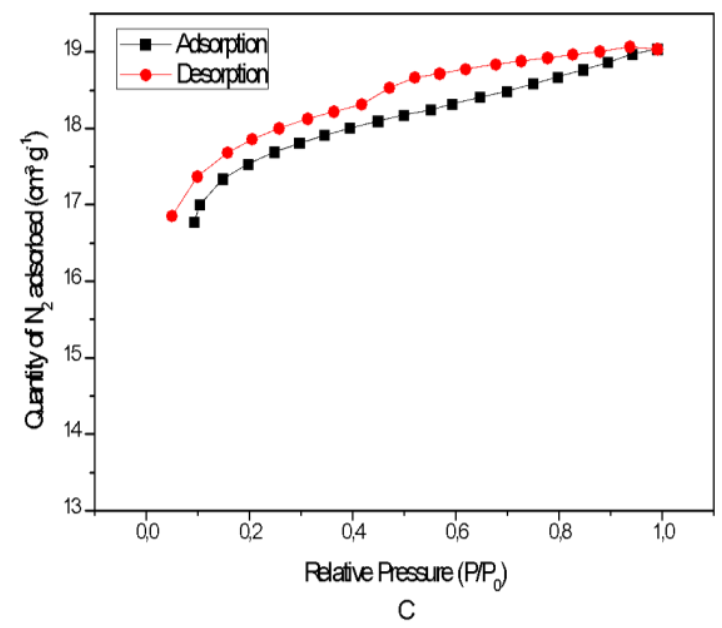

Figure 2 -. Adsorption/desorption isotherms for the activated carbon. 
The pore volume distribution was monomodal, with a well-defined maximum (Fig. 3). The pore diameters were concentrated in the range below $200 \AA$, with the greatest frequency at around $35 \AA$, as also found in the BJH textural analysis.

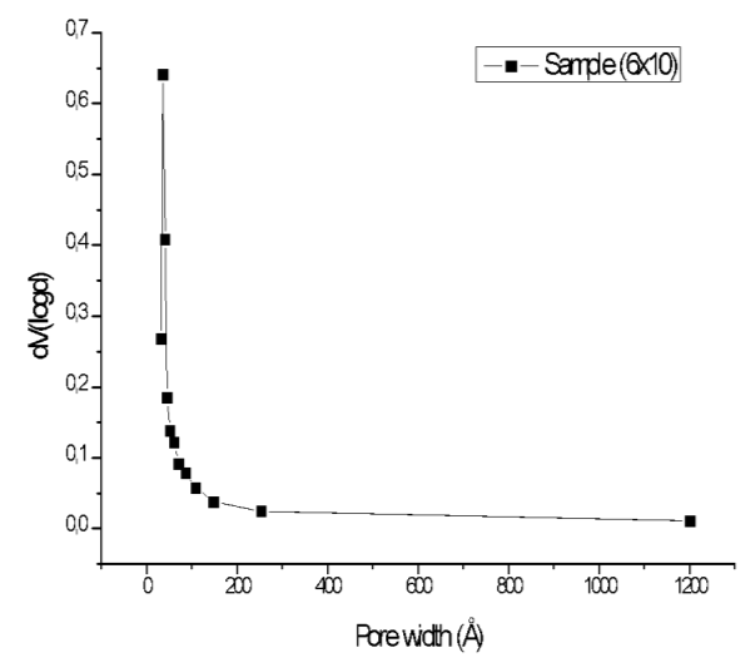

Figure 3 -. Pore volume distribution of the activated carbon $\left(\mathrm{dV}(\operatorname{logD}) \mathrm{cm} 3 \mathrm{~g}^{-1}\right)$.

The SEM micrographs (Fig. 4) revealed that the activated carbon consisted of particles ranging from 1 to $20 \mu \mathrm{m}$ in size, with irregular shapes.

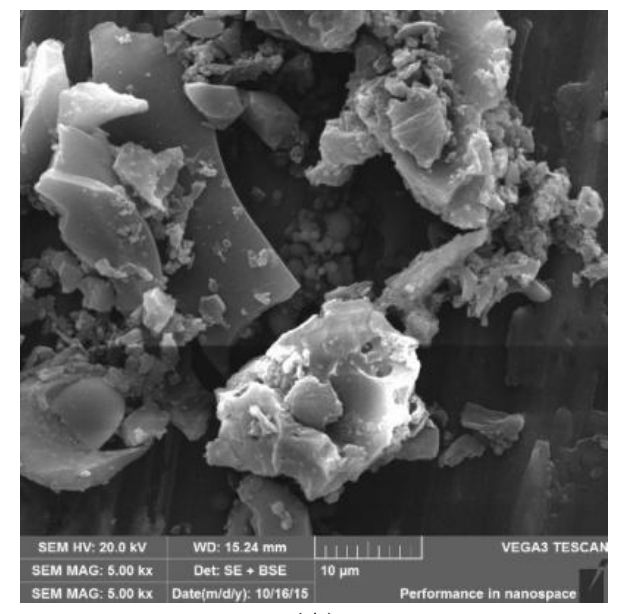

(A)

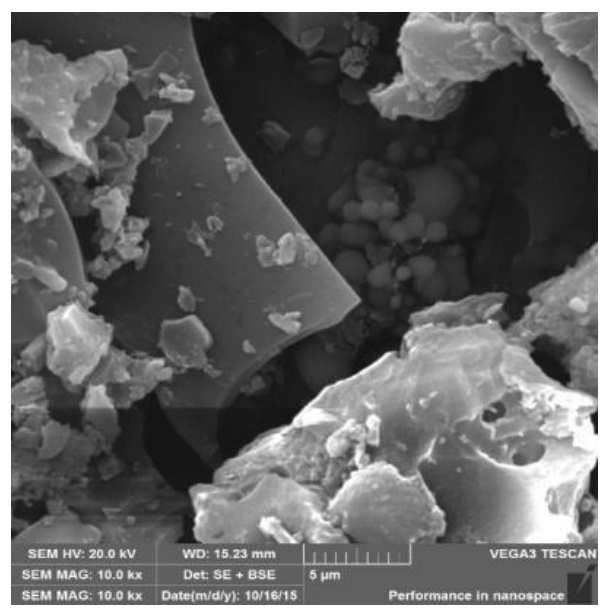

(B)

Figure 4 - SEM images of the activated carbon at magnifications of (A) 5000x and (B) 10000x.

After application of the factorial design in the experiments, the adsorbed methane mass storage capacities were obtained, which were converted to the volume of methane adsorbed according to the volume of the cylinder (V/V), as shown in Table 3, which also provides the results for the test using an empty cylinder (in the absence of adsorbent). 
Table 3 - Storage capacity of the activated carbon for methane (V/V)

\begin{tabular}{cc}
\hline Test & Sample \\
\hline $\mathbf{1}$ & 32.84 \\
$\mathbf{2}$ & 22.99 \\
$\mathbf{3}$ & 39.41 \\
$\mathbf{4}$ & 26.28 \\
$\mathbf{5}$ & 31.04 \\
$\mathbf{6}$ & 29.56 \\
$\mathbf{7}$ & 29.66 \\
Empty Cylinder & 13.14 \\
\hline
\end{tabular}

The volume of the storage cylinder was approximately $0.465 \mathrm{~L}$ and the tests using the activated carbon enabled attainment of a final volume of methane of $18.3 \mathrm{~L}$ (Test 3 ) at a pressure of 10 bar. In comparison with the test using an empty cylinder (without adsorbent), $\mathrm{CH}_{4}$ storage tripled, confirming the contribution of the bed filled with activated carbon.

A preliminary study of the efficiency of gas release was performed in order to determine the lowest temperature capable of achieving complete desorption of methane from the gas-solid system. This study showed that successful desorption was obtained at $60^{\circ} \mathrm{C}$.

In order to analyze the performance of the adsorption study and to determine the effects of the variables tested (temperature and flow rate), Pareto charts and response surface graphs were generated for the values (in liters) obtained in the tests, as shown in Figures 5 and 6.

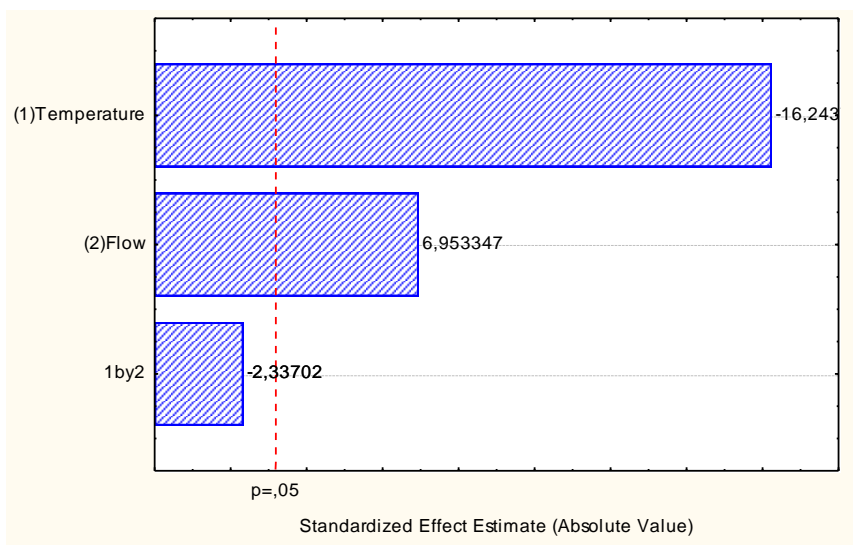

Figure 5 - Pareto chart for the experimental design using activated carbon.

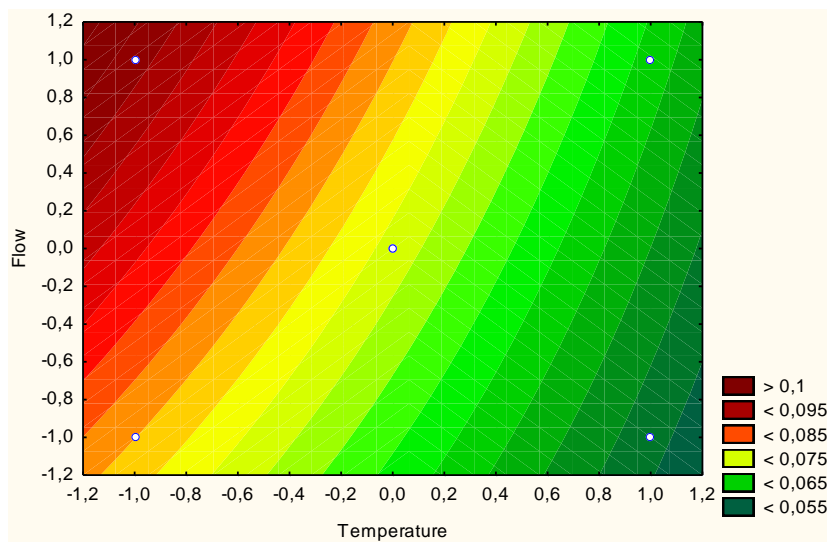

Figure 6 -. Response surface for the experimental design using activated carbon. 
The statistical analyses revealed the significance of both variables in the methane storage assays, according to the Pareto chart (Fig. 5), while the interaction of the variables did not show any significant positive effect. The best results were mainly achieved at lower temperatures, which could be explained by the exothermic nature of the adsorption process, with decrease of the temperature of the adsorption system thermodynamically favoring maintenance of the strengths of the active sites present in the carbon used.

A study was also undertaken to determine the performance of the activated carbon in sequential tests at $10 \mathrm{bar}$, using analyses of surface area and pore volume. After the tests, there was loss of only about $1.5 \%$ of the pore volume available for storage of $\mathrm{CH}_{4}$. These results indicated that there were no substantial changes in the structural characteristics of the carbon after the $\mathrm{CH}_{4}$ storage tests, and that the material could be reused without loss of its adsorption capacity.

\section{DISCUSSION}

Since activated carbons possess highly porous structures, typically with specific areas varying between 500 and $3000 \mathrm{~m}^{2} \mathrm{~g}^{-1}$, they are widely used in adsorption processes ${ }^{9}$. In the specific case of gas adsorption, as in this work (adsorption of methane), the activated carbon should present both micropores and mesopores, in order to facilitate the phenomenon of gas-solid diffusion. According to Antoniou et al. ${ }^{10}$, this characteristic favors a high capacity for adsorption of methane molecules.

The present findings also demonstrated that even after several sequential tests at 10 bar pressure, the carbon presented excellent mechanical resistance, since there were no significant losses in terms of specific area or pore volume, evidencing the potential for reuse of the material.

Therefore, the activated carbon met the requirements for a satisfactory methane adsorption process, since the average pore diameter was around $35 \AA$, corresponding to the lower mesopore range, with the additional presence of micropores.

Various studies have described the use of carbon as adsorbent in the methane adsorption process, but the systems used operated under pressures (around 35 bar) higher than employed in the present work. Here, an alternative low cost technique is proposed, suitable for small-scale operations, and the low working pressure (10 bar) provided a high storage yield, compared to other studies. For example, Prauchner and Rodríguez-Reinoso ${ }^{11}$ and Perrin et al. ${ }^{12}$ achieved storage capacities of $\sim 75$ and 95 $\mathrm{V} / \mathrm{V}$, respectively, using activated carbon at 35 bar pressure, while in the present work the capacity achieved was $\sim 48$ and $\sim 38 \%$ of the earlier values, respectively, but using only $28.6 \%$ of the pressure.

Another aspect of adsorption systems that should be considered is the desorption efficiency, since desorption is an endothermic process that requires a source of energy. After a preliminary study of desorption, a temperature of $60^{\circ} \mathrm{C}$ was considered ideal for total desorption of the methane present in the activated carbon. It should be noted that high efficiencies are more difficult to achieve in larger-scale systems, as described by Sahoo et al..$^{13}$, who reported efficiencies below $93 \%$ using a temperature of $80^{\circ} \mathrm{C}$.

\section{CONCLUSIONS}

This work reports the successful storage of $\mathrm{CH}_{4}$ at low pressure (10 bar) on a low cost adsorbent, tripling the storage capacity of the cylinder. In addition, the activated carbon could be effectively reused in sequential cycles, without showing any significant alterations in its structural characteristics. 
The best $\mathrm{CH}_{4}$ storage capacities were obtained at lower temperatures, due to the exothermic nature of the adsorption phenomenon.

The findings are important for the development of potential biogas/biomethane applications, especially in the vehicular sector, opening a range of possible scenarios for use of these fuels and contributing to the development of the sector.

\section{REFERENCES}

1. Coimbra-Araújo CH, Mariane L, Bley Jr C, Frigo EP, Frigo MS, Araújo IRC, et al. Brazilian case study for biogas energy: Production of electric power, heat and automotive energy in condominiums of agroenergy. Renewable and Sustainable Energy Reviews. 2014; 40: 826-839.

2. Chmielewski AG, Urbaniak A, Wawryniuk K. Membrane enrichment of biogas from twostage pilot plant using agricultural waste as a substrate. Biomass and Bioenergy. 2013; 58: 219-228.

3. Xiao Y, Yuan H, Pang Y, Chen S, Zhu B, Zou D, et al. $\mathrm{CO}_{2}$ Removal from Biogas by Water Washing System. Chinese Journal of Chemical Engineering. 2014; 22(8): 950-953.

4. Bordelanne O, Montero M, Bravin F, Prieur-Vernat A, Oliveti-Selmi O, Pierri H, et al Biomethane CNG hybrid: A reduction by more than $80 \%$ of the greenhouse gases emissions compared to gasoline. Journal of Gas Science and Engineering. 2011; 3(5): 617-624.

5. Åhman M. Biomethane in the transport sector - An appraisal of the forgotten option. Energy Policy. 2010; 38(1): 208-217.

6. Murphy JD, Browne J, Allen E, Gallagher C. The resource of biomethane, produced via biological, thermal and electrical routes, as a transport biofuel. Renewable Energy. 2013; 55: 474-479.

7. Policicchio A, Maccallini E, Agostino RE, Ciuchi F, Aloise A, Giordano G. Higher methane storage at low pressure and room temperature in new easily scalable large-scale production activated carbon for static and vehicular applications. Fuel. 2013; 104: 813821.

8. Sing KSW, Everett DH, Haul RAW, Moscou L, Pirotti RA, Rouquérol J, et al Reporting physisorption data for gas/solidsystems with special reference to the determination of surfasseáreana porosity. Pure and Applied Chemistry (IUPAC). 1985; 57(4): 603-619.

9. Oubagaranadin JUK, Murthy ZVP. Activated carbons: Classifications, properties and applications. In: James F. Kwiatkowski (Ed.). Activated Carbon: Classifications, Properties and Applications. Nova Science Publishers Inc, USA; 2011, p. 239-266.

10. Antoniou MK, Diamanti EK, Enotiadis A, Policicchio A, Dimos K, Ciuchi F, et al. Methane storage in zeolite-like carbon materials. Microporous and Mesoporous Materials. 2014; 188: 16-22.

11. Prauchner MJ, Rodríguez-Reinoso F. Preparation of granular activated carbons for adsorption of natural gas. Microporous and Mesoporous Material. 2008; 109: 581-584.

12. Perrin A, Celzard A, Marêché JF, Furdin G. Improved methane storage capacities by sorption on wet active carbons. Carbon. 2004; 42(7): 1249-1256.

13. Sahoo PK, Prajwal BP Dasetty SK, John M, Newalkar BL, Choudary NV, et al. Influence of exhaust gas heating and L/D ratios on the discharge efficiencies for an activated carbon natural gas storage system. Applied Energy. 2014; 119: 190-203. 